\title{
Effects of an Indigo Blanket on Insomnia Symptoms: Double Blind, Placebo-Controlled, Randomized Pilot Study
}

\author{
Young Nam Kwon ${ }^{1}$, Min Ji Sung ${ }^{1}$, Han A Cho ${ }^{1}$, Eunjoo Chang ${ }^{1}$, Kwang Ae Park², Jangwoon Park ${ }^{2}$, \\ Eun Jin Jeon ${ }^{3}$, Eunha Kim², Seunghoon Lee ${ }^{2}$, Heecheon You' ${ }^{2}$, Taeil Ha ${ }^{4}$, Won Chul Shin ${ }^{1}$ \\ ${ }^{1}$ Department of Neurology, Kyung Hee University Hospital at Gangdong, Kyung Hee University School of Medicine, Seoul, \\ ${ }^{2}$ Department of Industrial \& Management Engineering, POSTECH, Pohang, \\ ${ }^{3}$ Department of Clothing \& Science, Kyungpook National University, Daegu, \\ ${ }^{4}$ Yeongcheon Agricultural Technology \& Extension Center, Yeongcheon, Korea
}

쪽 이불의 불면증상에 미치는 효능: 이중맹검, 위약, 무작위 예비연구

권영남 ${ }^{1}$, 성민지 $^{1}$, 조한아 ${ }^{1}$, 장은주 ${ }^{1}$, 박광애 $^{2}$, 박장운 $^{2}$, 전은진 ${ }^{3}$, 김은하 $^{2}$, 이승훈 $^{2}$, 유희천 $^{2}$, 하태일 $^{4}$, 신원철 $^{1}$ 경희대학교 의과대학 강동경희대학교병원 신경과학교실, ${ }^{1}$ 포항공과대학교 산업경영공학과, ${ }^{2}$ 경북대학교 의류학과, ${ }^{3}$ 영천시농업기술센터 ${ }^{4}$

Received May 30, 2014 Revised June 23, 2014 Accepted June 23, 2014

Address for correspondence Won Chul Shin, MD Department of Neurology, Kyung Hee University Hospital at Gangdong, Kyung Hee University School of Medicine, 892 Dongnam-ro, Gangdong-gu, Seoul 134-727, Korea Tel: $+82-2-440-6166$ Fax: $+82-2-440-7262$ E-mail: shinwc@khu.ac.kr
Objectives: Transient insomnia symptoms are seen in about $30-50 \%$ of general population, which needs easily accessible and comfortable methods to improve the sleep quality. To assess the effect of indigo blanket on sleep promotion, we conducted a double-blind, placebo-controlled, randomized trial. Methods: Thirty subjects were recruited in this study and were randomly divided into two groups, indigo blanket and placebo blanket group. The subjects went to sleep with indigo or placebo blanket for one week. All subjects were asked to complete the sleep questionnaires [Insomnia Severity Index, Pittsburgh Sleep Quality Index, World Health Organization (WHO)-5 Well-Being Index] and to record the sleep diary before and after they use the blanket. The effects of each blanket was evaluated by sleep quality improvement and sleep satisfaction during their use of blanket, based on the sleep diary and sleep questionnaires. Results: Estimated total sleep time (268 min vs. $318 \mathrm{~min}$ ) was increased in indigo blanket group $(p<0.05)$. Estimated sleep latency and sleep efficacy, Pittsburgh Sleep Quality Index, WHO-5 Well-Being Index, and Insomnia Severity Index scores were not different among two groups. Conclusions: This pilot study suggests that the indigo blanket could have sleep promoting property and may warrant further research about effects of indigo blanket on sleep quality.

J Korean Sleep Res Soc 2014;11(1):33-37
서 론

불면증은 매우 흔한 수면장애로, 불면증의 정도와 상관없 이 성인 인구의 30 48\%에서는 불면증 증상을 겪고 있으며, 심각한 만성불면증(chronic insomnia)은 성인의 10 15\%에 서 관찰된다. ${ }^{1-3}$ 국내의 불면증 유병률은 전화설문을 통한 연 구에서 $22.8 \%$ 로 보고되었으며, ${ }^{4}$ 일반 인구의 약 $50 \%$ 가 수면 시간이 짧은 편에서 속하며, 인구의 약 $70 \%$ 가 최근 한 달간

This is an Open Access article distributed under the terms of the Creative Commons Attribution Non-Commercial License (http://creativecommons.org/licenses/by-nc/3.0) which permits unrestricted non-commercial use, distribution, and reproduction in any medium, provided the original work is properly cited.
수면문제를 느끼고 있는 것으로 조사되었다. ${ }^{5}$ 수면부족과 수 면 질 저하로 인해 주간졸음, 집중력 감소를 일으켜 졸음운전 이나 산업재해, 생산성 감소를 일으키며, ${ }^{6-10}$ 당뇨병이나, 동 맥경화증, 심혈관계 질환의 발생 확률을 높인다. ${ }^{11-14}$

불면증은 일반적으로 약물치료 및 수면위생, 수면인지행 동치료 등의 비약물치료로 치료하게 된다. 하지만 약물치료 는 장기적으로 사용할 경우 습관화가 생길 수 있으며, 중단 시 금단증상을 일으킬 수 있어 장기적으로 사용할 경우 심각 한 부작용을 야기시킬 수 있다. ${ }^{15}$ 수면인지행동치료는 비교 적 안전하고 장기간 치료 효과를 기대할 수 있으나, ${ }^{16}$ 비용이 비싸고, 전문가가 개입해야 하며, 치료효과가 나타나는 데 시 
간이 오래 걸리는 한계가 있다. ${ }^{17}$ 따라서 심각한 만성불면증 은 약물치료와 수면인지행동치료를 이용하여 치료해야 하 지만, 일시적 불면증이나 단기 불면증, 그리고 심하지 않은 불면증 환자들에게는 보다 안전하고, 비용이 적게 들며 손쉽 게 사용할 수 있는 치료법이 요구되고 있다.

고문헌에 숙면과 항염증 작용을 보인다고 기록되어져 있 는 천연염료인 쪽(polygonum indigo)을, ${ }^{18-20}$ 최근 영천농업 기술센터에서 천연발효방법을 이용한 쪽 염색방법을 개발하 였으며 이를 이용하여 쪽 이불을 만들어 직원들과 일반인들 에게 사용하게 한 결과, 수면의 질과 불면증 증상이 개선되는 임상적 경험을 하게 되었다. 본 연구는 쪽 염색된 이불에 대 한 수면의 질 개선 효과를 객관적으로 검증하고자, 심하지 않 은 단기 불면증상을 보이는 피험자들을 대상으로 쪽 염색 제 품으로 제작한 쪽 이불과 일반 이불을 1 주간 사용하여 비교 평가하였으며, 무작위 배정, 이중눈가림연구로 진행하였다.

\section{방 법}

\section{대 상}

2013년 2월부터 8월까지 강동경희대병원 수면센터에 내 원한 환자와 강동경희대병원 홈페이지 게시와 원내 게시물 을 통해 연구대상자 모집공고를 내어 불면증 증상과 수면의 질 저하를 호소하는 피험자를 대상으로 하였다.

본 연구의 피험자 선정기준은 다음과 같다. 1) 연구시작 한 달 이내에 잠들기 어려움, 수면유지의 어려움, 회복이 되지 않는 수면 등의 증상 중 한 가지를 보이는 30세 이상의 성인, 2) 수면이력설문지(Sleep History Questionnaire)에 의해 불 면증으로 확인된 환자, ${ }^{21}$ 3) 이전에 불면증에 대한 수면제를 복용하지 않은 환자.

본 연구의 피험자 제외 기준은 다음과 같다. 1) 불면증이 한 달 이상 지속된 만성 불면증 환자, 2) 라스킨우울척도(Raskin Depression Scale)에 의해 평가되는 우울증 환자(총 점수 6 이상인 피험자), 3) 코비불안척도(Covi Anxiety Scale)에 의 해 평가되는 불안장애(총 점수 6 이상인 피험자), 4) 간이정신 상태검사(Mini Mental State Examination)로 평가되는 치매 환자(24점 이하로 평가된 피험자), 5) 정신질환, 특히, 정신이 상, 우울증 기왕력자, 6) 연구 3개월 이내 및 임상시험 기간 동 안 정신작용약물을 복용한 경우, 7) 시험참여 이전 2주간 벤 조디아제핀계(benzodiazepine) 또는 다른 수면제의 사용이 있었던 경우[졸피뎀(zolpidem), 바르비탈계 약물(barbiturates), 부스피론(buspirone), 히드록시진(hydroxyzine)], 8) $\mathrm{ASAT}(\mathrm{SGOT}) / \mathrm{ALAT}(\mathrm{SGPT})$ 가 정상 상한치의 3배 초과인 간질환, $\mathrm{GGT}$ (감마글루타밀기전이효소)가 정상 상한치의 2
배 초과한 경우, 만성 알코올 중독으로 인한 $\mathrm{MCV}$ (평균혈구 용적)가 $95 \mathrm{fL}$ 초과인 경우, 크레아티닌 수치가 $150 \mu \mathrm{mol} / \mathrm{L}$ 를 초과하는 신부전 환자, 9) 약물남용자 또는 기왕력자(알코올 포함), 10) 중증의 신경질환 또는 뇌신경수술 기왕력자, 11) 수 면에 영향을 줄 수 있는 중증의 통증이 동반된 환자, 12) 알코 올, 커피, 차를 과하게 섭취하는 피험자(1일 순 알코올로 $30 \mathrm{~g}$ 과 동등 이상 섭취, 하루 7잔 이상의 커피나 차 섭취), 야간 담 배 흡연자 또는 하루 15 개비 이상의 담배 흡연자, 불규칙한 생 활방식을 가진 환자(예; 교대근무자, 시차증을 가진 피험자 등).

\section{방 법}

본 연구는 쪽 이불이 수면의 질에 영향을 미치는지에 대한 예비연구로, 피험자 선정기준을 만족한 30명을, 피험자 등록 순서에 따라 $1: 1$ 비율로 쪽 이불군과 일반 이불군으로 무작 위 배정하였다.

임상시험을 하기 전에 불면증 심각도 지수(Insomnia Severity Index), 피츠버그 수면 질 지수(Pittsburgh Sleep Quality Index), 세계보건기구 삶의 질 지수(World Health Organization-5 Well-Being Index 1998 version) 등의 설문지를 작성 하여 불면증의 정도를 측정하였다..$^{22-25}$ 스크리닝 방문에서 선정기준에 적합하지 않은 피험자는 시험에서 제외하였다. 스크리닝과 선정/제외기준에 적합한 피험자들은 이불 사용 이전 1 주일간의 수면일기를 작성하여 평소 수면습관을 측정 하였다. 수면 만족도는 하루 2회 측정하였으며, 아침 기상 후 “지난 밤 잠자리에 대해 어떻게 느끼십니까?”에 대한 환 자의 주관적인 평가로 '매우 안 좋다'에서 '매우 좋다'까지 총 5단계로 답하도록 하였고(satisfaction for night time), 잠자 리에 들기 전에 “오늘 낮에 대해 어떻게 느끼십니까”라는 질 문에 대한 평가를 역시 5단계로 나누어 주관적으로 답하도 록 하였다(satisfaction for day time). 수면 만족도는 마지막 3 일간의 낮과 밤에 대한 수면 만족도의 평균을 구하여 분석 하였다. 피험자를 쪽 염색 제품으로 제작한 쪽 이불군과 쪽 이불과 같은 색과 모양의 일반 이불군 15 명으로 무작위로 $1: 1$ 배정하였다. 각각의 환자군은 1 주간 저녁 수면시간에 이 불을 덮고 잤으며, 매일 아침 수면일기를 측정하였다. 1 주일 후, 매일 작성한 수면일기를 수거하여 마지막 3일간의 낮과 밤에 대한 수면 만족도의 평균을 구하였으며, 불면증 심각도 지수, 피츠버그 수면 질 지수, 세계보건기구 삶의 질 지수 등 의 설문지를 다시 작성하였다. 작성된 피츠버그 수면 질 지 수 설문지 문항에서 "지난 1주 동안 몇 시에 잠자리에 들었 습니까?”라는 질문의 답을 취침시각, “지난 1 주 동안 아침에 몇 시에 일어났습니까?”라는 질문의 답을 기상시각으로 정 하였다. 또한, “밤에 잠드는 데 얼마나 오래 걸렸습니까?”라 
는 질문의 답을 수면잠복기로 정하였고, "지난 1 주 동안 밤에 실제로 잠잔 시간은 하루에 평균 얼마나 됩니까?”라는 질문 의 답을 총 수면시간으로 정하였으며, 수면 효율은 취침시각 과 기상시각 사이의 시간 중 총 수면시간의 비율로 정하였다.

쪽 이불의 효과를 평가하는 일차 유효성 평가변수는 임상 시험 전후의 수면잠복기, 총 수면시간, 수면 효율의 변화로 하였으며, 이차 유효성 평가변수로는 불면증 심각도 지수, 피 츠버그 수면 질 지수, 세계보건기구 삶의 질 지수, 수면 만족 도의 변화를 통해 평가하였다.

피험자의 일반적 특성은 실수와 백분율을 사용하였고 두 군 간의 차이는 independent and paired t-test, one-way analysis of variance(ANOVA) and $\chi^{2}$-test를 사용하여 분석하였 으며, 쪽 이불의 수면의 질에 미치는 영향은 쪽 이불군과 일 반 이불군에 수집된 데이터를 반복측정분산분석(repeatedmeasured ANOVA)을 이용하여 비교 분석하였고, 분석의 결과는 $p$ 값을 0.05 로 하여 유의성을 확인하였다.

본 시험은 강동경희대학교병원 임상시험심사위원회(Institutional Review Board)의 승인을 받은 시험계획서에 따 라 진행되었다.

\section{결 과}

본 연구의 피험자는 발효 쪽 염색 제품으로 제작한 쪽 이불

Table 1. Baseline characteristics of indigo blanket and placebo blanket group

\begin{tabular}{lccc}
\hline & $\begin{array}{c}\text { Indigo blanket } \\
\text { group }\end{array}$ & $\begin{array}{c}\text { Control } \\
\text { group }\end{array}$ & $p$ \\
\hline Age & $44.1 \pm 10.7$ & $45.2 \pm 15.9$ & 0.820 \\
SL & $44.7 \pm 27.2$ & $50.7 \pm 25.1$ & 0.535 \\
TST & $268.0 \pm 62.6$ & $284.0 \pm 67.0$ & 0.505 \\
SE & $71.01 \pm 18.68$ & $73.80 \pm 11.96$ & 0.631 \\
ISI & $14.40 \pm 3.23$ & $16.20 \pm 3.65$ & 0.163 \\
PSQI & $10.87 \pm 2.33$ & $11.60 \pm 2.41$ & 0.404 \\
WHO-5 Index & $10.00 \pm 3.33$ & $10.00 \pm 4.14$ & 1.000 \\
Diary & & & \\
$\quad$ QON & $2.67 \pm 0.55$ & $2.42 \pm 0.56$ & 0.236 \\
$\quad$ QOD & $2.84 \pm 0.55$ & $2.57 \pm 0.46$ & 0.144 \\
Raskin Depression & $1.33 \pm 0.90$ & $1.20 \pm 1.08$ & 0.716 \\
Scale & & & \\
Covi Anxiety Scale & $1.40 \pm 0.51$ & $1.40 \pm 0.51$ & 1.000 \\
MMSE & $28.87 \pm 2.00$ & $29.53 \pm 1.06$ & 0.266 \\
\hline
\end{tabular}

Numbers are mean \pm standard deviation. ISI: Insomnia Severity Index, MMSE: Mini Mental State Examination, PSQI: Pittsburgh Sleep Quality Index, QOD: quality of day, QON: quality of night, SL: sleep latency, SE: sleep efficacy, TST: total sleep time
군 15 명과 쪽 이불과 같은 색과 모양의 일반 이불군 15 명이 었다. 평균 연령은 44.6 \pm 13.3 세였고 양 군 간의 유의한 차이 는 보이지 않았다. 라스킨우울척도, 코비불안척도, 간이정신 상태검사에서도 양 군 간의 유의한 차이는 보이지 않았으며, 수면의 질을 알아보기 위한 불면증 심각도 지수, 피츠버그 수 면 질 지수, 세계보건기구 삶의 질 지수 및 수면 만족도에서 도 유의한 차이를 보이지 않았다. 또한 객관적 수면 지표인 수면잠복기, 총 수면시간, 수면효율에서도 양 군 간의 유의한 차이를 보이지 않아 무작위로 배정된 두 그룹은 차이가 없 었다(Table 1).

쪽 이불군에서 쪽 이불 사용 전후의 수면의 질을 평가하였 다(repeated measure ANOVA), 쪽 이불군과 일반 이불군을 비교하였을 때, 쪽 이불 사용 전에 비하여 쪽 이불 사용 후에 총 수면시간이 유의하게 증가하였으나 $(p=0.041)$, 수면효율, 입면잠복시간, 피츠버그 수면 질 지수점수, 세계보건기구 삶 의질 지수, 불면증 심각도 지수, 밤과 낮의 수면 만족도는 통 계적으로 유의한 차이가 없었다(Table 2).

쪽 이불과 일반 이불에 대한 부작용 보고는 전혀 없었다.

\section{고 찰}

본 연구에서는 쪽 이불을 사용한 실험군에서 사용 전에 비 해 통계적으로 유의하게 총 수면시간이 증가함이 확인되었 으나, 피츠버스 수면 질 지수로 조사한 전반적 수면의 질 및 수면효율, 입면잠복시간, 불면증 심각도 지수, 밤과 낮의 수 면 만족도는 양 군 간 차이를 보이지 않았다. 이는 쪽 이불이 수면의 질을 일부 개선시킬 가능성이 있음을 시사한다.

불면증은 전체 성인의 약 30 48\%의 유병률을 보이는 매우 흔한 수면장애이지만, 67 Ohayon의 조사에 의하면 전체 불면 증 환자의 약 $6 \%$ 만 불면증으로 진단받아 치료를 받고 있다. ${ }^{2}$ 불면증이 치료의 대상이 되는 질병이 아니고 개인이 감수해 야 할 불편으로 생각하는 인식과, 또한 기존의 불면증 치료 에 사용되는 약물치료와 수면인지행동치료가 부작용과 습관 성, 고가의 비용, 전문가의 개입이 되어야 해서 치료에 대한 접근이 쉽지 않기 때문에 높은 유병률을 보이는 불면증 환자 들 중 실제로 매우 적은 환자만 전문적 치료를 받게 되며, 대 부분의 환자들은 효과에 대해 체계적으로 검증이 되지 않은 민간요법이나 경험에 의한 방법들을 불면증상 개선을 위해 서 사용하고 있다.

기존의 치료법을 보완하고, 수면의 질을 개선시킬 수 있는 보다 간편하면서 안전하고, 적은 비용으로 일상에서 누구나 전문가 도움 없이 쉽게 접근할 수 있는 객관적인 방법에 대 한 연구가 진행되어 왔다. 대표적으로 쥐오줌풀(valeria), 인삼 
Table 2. Comparison with indigo blanket and placebo blanket group on sleep promoting effect

\begin{tabular}{|c|c|c|c|c|c|c|}
\hline & & & Before & After & $\mathrm{F}$ & $p$ \\
\hline \multirow{2}{*}{\multicolumn{2}{|c|}{$\overline{\mathrm{SL}}$}} & Experimental & $44.7( \pm 27.2)$ & $50.7( \pm 25.1)$ & 0.005 & 0.947 \\
\hline & & Control & $40.7( \pm 30.8)$ & $46.0( \pm 27.2)$ & & \\
\hline \multirow{2}{*}{\multicolumn{2}{|c|}{ TST }} & Experimental & $268.0( \pm 62.6)$ & $284.0( \pm 67.0)$ & 4.595 & $0.041^{*}$ \\
\hline & & Control & $318.0( \pm 40.6)$ & $289.3( \pm 52.7)$ & & \\
\hline \multirow{2}{*}{\multicolumn{2}{|c|}{ SE }} & Experimental & $71.0( \pm 18.7)$ & $73.8( \pm 12.0)$ & 0.272 & 0.606 \\
\hline & & Control & $76.2( \pm 11.9)$ & $76.9( \pm 11.6)$ & & \\
\hline \multirow{2}{*}{\multicolumn{2}{|c|}{ ISI }} & Experimental & $14.40( \pm 3.23)$ & $16.20( \pm 3.65)$ & 0.177 & 0.677 \\
\hline & & Control & $11.47( \pm 2.88)$ & $13.87( \pm 4.05)$ & & \\
\hline \multirow{2}{*}{\multicolumn{2}{|c|}{ PSQI }} & Experimental & $10.87( \pm 2.33)$ & $11.60( \pm 2.41)$ & 1.351 & 0.255 \\
\hline & & Control & $9.40( \pm 1.30)$ & $11.13( \pm 2.17)$ & & \\
\hline \multirow{2}{*}{\multicolumn{2}{|c|}{ WHO-5 Index }} & Experimental & $10.00( \pm 3.33)$ & $10.00( \pm 4.14)$ & 0.069 & 0.794 \\
\hline & & Control & $10.87( \pm 3.02)$ & $11.20( \pm 4.13)$ & & \\
\hline \multirow[t]{4}{*}{ Diary } & QON & Experimental & $2.67( \pm 0.55)$ & $2.42( \pm 0.56)$ & 0.051 & 0.823 \\
\hline & & Control & $2.81( \pm 0.68)$ & $2.69( \pm 0.67)$ & & \\
\hline & QOD & Experimental & $2.84( \pm 0.55)$ & $2.57( \pm 0.46)$ & 0.169 & 0.684 \\
\hline & & Control & $3.10( \pm 0.55)$ & $2.88( \pm 0.66)$ & & \\
\hline
\end{tabular}

Numbers are mean \pm standard deviation, repeated measured analysis of variance. ${ }^{*} p<0.05$. ISI: Insomnia Severity Index, PSQI: Pittsburgh Sleep Quality Index, QOD: quality of day, QON: quality of night, SL: sleep latency, SE: sleep efficacy, TST: total sleep time

(panax), 시계초(passiflora) 등의 식물을 이용한 방법과, 방향 (aroma), 침구류 등의 수면 환경을 이용한 방법이 있다. ${ }^{26-28}$ 쥐오줌풀은 valepotriates 성분을 포함하고 있어 gamma-aminobutyric acid(GABA) 수용체와 상호작용하여 중추신경계 에서 진정작용을 하며, 인삼은 ginsenoside 성분이, 시계초는 인돌알칼로이드, 말톨 등의 성분이 GABA 수용체와 상호작 용을 하여 수면 유지에 도움에 된다고 보고되었다. ${ }^{26}$ 이들의 정확한 기전은 알려지지 않았지만 감정상태의 안정과 항불 안효과로 수면의 질에 영향을 미칠 수 있는 많은 요소들과 관 련이 있을 것으로 추측하고 있다. ${ }^{29}$ 라벤더 아로마를 통한 흡 입법은 부교감신경계를 강화시키고, 심박동수를 낮추며, 심 박변이성(heart rate variability)을 호전시켜 수면장애의 개선 과 우울 및 스트레스 감소를 일으킬 수 있다. ${ }^{30}$ 또한 아로마 마 사지는 교감신경의 흥분을 감소시킴으로써 혈압 강하와 수 면의 질 개선에도 영향을 준다는 보고가 있다. ${ }^{31}$

침구류를 이용한 치료법으로 수면의 질을 향상시키려는 연구도 있었다. 매트리스의 재질과 모양은 잠자는 동안 몸을 움직이는 정도와 이로 인한 수면의 질 변화에 영향을 미칠 수 있고, 매트리스의 스프링은 수면 자세의 안정성에 영향을 주 는 중요한 요소로 알려져 있다. 32 매트리스의 강도에 따라서 교감신경계를 조정하여 심박변이성과 동맥혈압변이성(arterial pressure variability)이 감소하고, 수면 중 심장 미주 신 경 활동(cardiac vagal activity), 압수용기 반사 감도(baroreceptor reflex sensitivity)가 증가할 수도 있으며, ${ }^{33}$ 이불의 재
질의 특성에 따라 편안함을 주거나 온도와 습도 등의 수면 환 경에 변화를 줄 수 있고, ${ }^{34}$ 침구류의 종류와 고온 및 저온에 노출시킴에 따라 온도가 변함으로써, 체온조절 및 이와 연관 된 수면단계의 변화와 연관이 있다는 연구가 있었다..$^{35}$

본 연구는 천연 염색된 쪽 이불에 의한 수면의 질 개선효과 를 알아본 최초의 연구이며, 비록 적은 피험자들을 대상으로 한 예비연구이지만 쪽 이불이 일부 수면의 질 개선을 시킬 수 있는 가능성을 시사한다. 본 연구에서 사용한 쪽 이불은 단순 히 색이 염색되는 일반 염색법과는 달리, 색소의 성분인 인디 고(indigo)가 환원과 산화의 과정을 거치면서 안료상태로 섬 유에 흡착되어 염색됨으로써 항암 효과, 항돌연변이 효과뿐 만 아니라 항균, 항염증 효과를 가지는 인디고의 한 성분인 인디루빈이 보다 많이 섬유에 침착되게 된다. 36,37 쪽 이불의 수면의 질 개선효과에 대한 정확한 기전은 알 수 없으나, 인 디루빈이 가지고 있는 항염증효과가 자율신경계를 조절하고 진정작용을 보여 불면증상을 개선하는 것으로 추정된다. 이 에 대해서는 향후 자율신경검사 등의 생리학적 검사와 항염 증효과에 대한 혈액검사 등을 이용하여 보다 객관적인 평가 를 통해 쪽 이불이 수면의 질 개선을 일으키는 기전과 평가가 필요하다.

본 연구가 비록 쪽 이불의 수면의 질 개선효과를 확인하기 위해서 실험군과 대조군으로 무작위배정, 이중눈가림연구로 진행하였으나, 단일 센터에서 적은 피험자를 대상으로 하였 으며, 보다 정밀하게 수면의 질을 측정할 수 있는 수면다원검 
사와 같은 객관적인 검사가 아닌 피험자의 주관적인 만족도 와 설문지만으로 수면 질을 평가한 점은 본 연구의 한계라 할 수 있다. 또한 7일간의 비교적 짧은 시간 동안의 쪽 이불 사 용효과를 측정하였는데, 장기간 사용하였을 때의 효과와 문 제점에 대한 평가가 이루어지지 못하였다. 향후 이에 대한 추가적인 연구가 필요할 것이다.

\section{Acknowledgments}

This work is financially supported by Korea Ministry of Environment (MOE) as "EcoDesign Human Resource Development Project".

\section{REFERENCES}

1. Schutte-Rodin S, Broch L, Buysse D, Dorsey C, Sateia M. Clinical guideline for the evaluation and management of chronic insomnia in adults. J Clin Sleep Med 2008;4:487-504.

2. Ohayon MM. Epidemiology of insomnia: what we know and what we still need to learn. Sleep Med Rev 2002;6:97-111.

3. National Institutes of Health. National Institutes of Health State of the Science Conference statement on Manifestations and Management of Chronic Insomnia in Adults, June 13-15, 2005. Sleep 2005;28:1049-1057.

4. Cho YW, Shin WC, Yun CH, Hong SB, Kim J, Earley CJ. Epidemiology of insomnia in korean adults: prevalence and associated factors. J Clin Neurol 2009;5:20-23.

5. Woo JM, Hyun SY, Lee SH, et al. Productivity time lost by sleep disturbance among workers in Korea. J Korean Neuropsychiatr Assoc 2011; 50:62-68.

6. Bastien CH, Fortier-Brochu E, Rioux I, LeBlanc M, Daley M, Morin $\mathrm{CM}$. Cognitive performance and sleep quality in the elderly suffering from chronic insomnia. Relationship between objective and subjective measures. J Psychosom Res 2003;54:39-49.

7. Cricco M, Simonsick EM, Foley DJ. The impact of insomnia on cognitive functioning in older adults. J Am Geriatr Soc 2001;49:1185-1189.

8. Haimov I, Hanuka E, Horowitz Y. Chronic insomnia and cognitive functioning among older adults. Behav Sleep Med 2008;6:32-54.

9. Hauri PJ. Cognitive deficits in insomnia patients. Acta Neurol Belg 1997; 97:113-117.

10. Szelenberger W, Niemcewicz S. Severity of insomnia correlates with cognitive impairment. Acta Neurobiol Exp (Wars) 2000;60:373.

11. Vgontzas AN, Liao D, Pejovic S, Calhoun S, Karataraki M, Bixler EO. Insomnia with objective short sleep duration is associated with type 2 diabetes: a population-based study. Diabetes Care 2009;32:1980-1985.

12. Schwartz S, McDowell Anderson W, Cole SR, Cornoni-Huntley J, Hays JC, Blazer D. Insomnia and heart disease: a review of epidemiologic studies. J Psychosom Res 1999;47:313-333.

13. Kripke DF, Garfinkel L, Wingard DL, Klauber MR, Marler MR. Mortality associated with sleep duration and insomnia. Arch Gen Psychiatry 2002;59:131-136.

14. King CR, Knutson KL, Rathouz PJ, Sidney S, Liu K, Lauderdale DS. Short sleep duration and incident coronary artery calcification. JAMA 2008;300:2859-2866.

15. Balter MB, Uhlenhuth ET. New epidemiologic findings about insomnia and its treatment. J Clin Psychiatry 1992;53:34-39.
16. Ebben MR, Spielman AJ. Non-pharmacological treatments for insomnia. J Behav Med 2009;32:244-254.

17. Morin CM, Vallières A, Guay B, et al. Cognitive behavioral therapy, singly and combined with medication, for persistent insomnia: a randomized controlled trial. JAMA 2009;301:2005-2015.

18. Hoessel R, Leclerc S, Endicott JA, et al. Indirubin, the active constituent of a Chinese antileukaemia medicine, inhibits cyclin-dependent kinases. Nat Cell Biol 1999;1:60-67.

19. Kim SA, Kim YC, Kim SW, et al. Antitumor activity of novel indirubin derivatives in rat tumor model. Clin Cancer Res 2007;13:253-259.

20. Li Y, Ligr M, McCarron JP, et al. Natura-alpha targets forkhead box m1 and inhibits androgen-dependent and -independent prostate cancer growth and invasion. Clin Cancer Res 2011;17:4414-4424.

21. Parrott AC, Hindmarch I. Factor analysis of a sleep evaluation questionnaire. Psychol Med 1978;8:325-329.

22. Bastien CH, Vallières A, Morin CM. Validation of the Insomnia Severity Index as an outcome measure for insomnia research. Sleep Med 2001; 2:297-307.

23. Buysse DJ, Ancoli-Israel S, Edinger JD, Lichstein KL, Morin CM. Recommendations for a standard research assessment of insomnia. Sleep 2006;29:1155-1173.

24. Backhaus J, Junghanns K, Broocks A, Riemann D, Hohagen F. Test-retest reliability and validity of the Pittsburgh Sleep Quality Index in primary insomnia. J Psychosom Res 2002;53:737-740.

25. Bech P, Olsen LR, Kjoller M, Rasmussen NK. Measuring well-being rather than the absence of distress symptoms: a comparison of the SF36 Mental Health subscale and the WHO-Five Well-Being Scale. Int $J$ Methods Psychiatr Res 2003;12:85-91.

26. Attele AS, Xie JT, Yuan CS. Treatment of insomnia: an alternative approach. Altern Med Rev 2000;5:249-259.

27. Van Deun D, Verhaert V, Willemen T, et al. Biomechanics-based active control of bedding support properties and its influence on sleep. Work 2012;41 Suppl 1:1274-1280.

28. Tanaka J, Uchimura N, Hashizume Y, et al. Effects of aroma on sleep and biological rhythms. Psychiatry Clin Neurosci 2002;56:299-300.

29. Wheatley D. Medicinal plants for insomnia: a review of their pharmacology, efficacy and tolerability. J Psychopharmacol 2005;19:414-421.

30. Chien LW, Cheng SL, Liu CF. The effect of lavender aromatherapy on autonomic nervous system in midlife women with insomnia. Evid Based Complement Alternat Med 2012;2012:740813.

31. Koulivand PH, Khaleghi Ghadiri M, Gorji A. Lavender and the nervous system. Evid Based Complement Alternat Med 2013;2013:681304.

32. Shen L, Chen YX, Guo Y, et al. Research on the relationship between the structural properties of bedding layer in spring mattress and sleep quality. Work 2012;41 Suppl 1:1268-1273.

33. Kuo TB, Li JY, Lai CT, Huang YC, Hsu YC, Yang CC. The effect of bedding system selected by manual muscle testing on sleep-related cardiovascular functions. Biomed Res Int 2013;2013:937986.

34. Okamoto K, lizuka S, Okudaira N. The effects of air mattress upon sleep and bed climate. Appl Human Sci 1997;16:97-102.

35. Okamoto-Mizuno K, Mizuno K. Effects of thermal environment on sleep and circadian rhythm. J Physiol Anthropol 2012;31:14.

36. Han SY, Choi SC. A study on the physiological effects and dyeing properties of the extract of fermented (Part I). JKSCT 2000;24:96-104.

37. Han SY, Choi SC. A study on the physiological effects and dyeing properties of the extract of fermented (Part II). JKSCT 2000;24:1146-1154. 